\title{
Feasibility of home management using ACT for childhood malaria episodes in an urban setting
}

This article was published in the following Dove Press journal:

Drug, Healthcare and Patient Safety

28 December 201I

Number of times this article has been viewed

\author{
Dickson S Nsagha ${ }^{1,2}$ \\ Jean-Bosco N Elat ${ }^{2,3}$ \\ Proper AB Ndong ${ }^{2,4}$ \\ Peter N Tata ${ }^{2,5}$ \\ Maureen-Nill N Tayong ${ }^{2}$ \\ Francois F Pokem ${ }^{2}$ \\ Christian C Wankah ${ }^{6}$ \\ 'Department of Public Health and \\ Hygiene, Faculty of Health Sciences, \\ University of Buea, Buea, Cameroon; \\ ${ }^{2}$ Public Health Research Group, \\ Yaounde, Cameroon; ${ }^{3}$ National AIDS \\ Control Committee, Ministry of \\ Public Health, Cameroon; ${ }^{4}$ National \\ Malaria Control Programme, \\ Ministry of Public Health, Cameroon; \\ ${ }^{5}$ Department of Anthropology, Faculty \\ of Arts, Letters and Social Sciences, \\ University of Yaounde I, Yaounde, \\ Cameroon; ${ }^{6}$ Department of Public \\ Health, Faculty of Medicine and \\ Biomedical Sciences, University of \\ Yaounde I, Yaounde, Cameroon
}

Correspondence: Dickson S Nsagha Department of Public Health and Hygiene, Faculty of Health Sciences, University of Buea, Box 63, Buea,

Cameroon

Tel +23777499429

Fax +2373322272

Email nsaghads@hotmail.com
Background: Over 90\% of malaria cases occur in Sub-Saharan Africa, where a child under the age of 5 years dies from this illness every 30 seconds. The majority of families in SubSaharan Africa treat malaria at home, but therapy is often incomplete, hence the World Health Organization has adopted the strategy of home management of malaria to solve the problem. The purpose of this study was to determine community perception and the treatment response to episodes of childhood malaria in an urban setting prior to implementation of home management using artemisinin-based combination therapy (ACT).

Methods: This qualitative exploratory study on the home management of malaria in urban children under 5 years of age used 15 focus group discussions and 20 in-depth interviews in various categories of caregivers of children under 5 years. One hundred and eighteen people participated in the focus group discussions and 20 in the in-depth interviews. The study explored beliefs and knowledge about malaria, mothers' perception of home management of the disease, health-seeking behavior, prepackaged treatment of malaria using ACT and a rapid diagnostic test, preferred channels for home management of uncomplicated malaria, communication, the role of the community in home management of malaria, and the motivation of drug distributors in the community.

Results: The mothers' perception of malaria was the outcome of events other than mosquito bites. Home treatment is very common and is guided by the way mothers perceive signs and symptoms of malaria. Frequent change of malarial drugs by the national health policy and financial difficulties were the main problems mothers faced in treating febrile children. Rapid diagnostic testing and prepackaged ACT for simple malaria in children under 5 years would be accepted if it was offered at an affordable price. Tribalism and religious beliefs might hinder the delivery of home management of malaria. The availability of rapid diagnostic testing and ACT all year round is one of the challenges of home management of malaria. Although radio and television featured among the current sources of information within the community, meetings, churches, schools, and other public gatherings were the best venues for social mobilization, while community health workers and community leaders were the best sensitization agents for positive behavior change to adhere to home management of malaria. Monetary incentives should be offered to community drug distributors. This should be deducted from the combined price of ACT and rapid diagnostic testing.

Conclusion: For successful implementation of home management of malaria, there should be proper education, social mobilization of the population, and continuous monitoring and evaluation of field activities to ensure adequate stocks of ACT and rapid diagnostic testing within the framework of the intervention.

Keywords: malaria, home management, children, urban, rapid diagnostic test, artemisinin-based combination therapy, Cameroon submit your manuscript $\mid$ www.dovepress.com

Dovepress

http://dx.doi.org/10.2147/DHPS.S25406
Drug, Healthcare and Patient Safety 2012:4 I-18

(C) 2012 Nsagha et al, publisher and licensee Dove Medical Press Ltd. This is an Open Access article which permits unrestricted noncommercial use, provided the original work is properly cited. 


\section{Introduction}

Over $90 \%$ of malaria cases occur in Sub-Saharan Africa, where nearly all deaths due to the disease occur in children under 5 years of age. ${ }^{1}$ Every 30 seconds, a child under 5 years dies of malaria in Sub-Saharan Africa. ${ }^{2}$ Malaria, which was believed to be a disease of rural areas in Africa, is gradually emerging as a new phenomenon in the urban area. ${ }^{3}$ In Sub-Saharan Africa, urban malaria has been recognized in Yaoundé, Lagos, Accra, Kumasi, Dar es Salam, and many other cities. ${ }^{4,5}$ In these cities, the prevalence of malaria is highest among the poorer sections of the population. Some contributing factors include poor sanitation, poor housing, environmental degradation, and urban agriculture.

A number of studies have shown that the majority of families in Sub-Saharan Africa treat malaria at home, but that treatment is often incomplete or inadequate. ${ }^{1}$ In response to this malaria problem, a package of interventions for the home management of uncomplicated malaria (HMM) in children under 5 years, developed and tested through multicountry studies in Nigeria, ${ }^{6,7}$ Kenya, ${ }^{8,9}$ and Burkina Faso, ${ }^{10,11}$ and found to be effective for control of the disease, was recommended by the Roll Back Malaria initiative of the World Health Organization (WHO) to scale up the fight against this disease. ${ }^{12}$ However, all the previous studies used chloroquine, which is now obsolete, hence the need to produce evidence on the feasibility, acceptability, and safety of HMM using artemisinin-based combination therapy (ACT, comprising amodiaquine + artesunate).

Reviews of research conducted to understand people's perception and treatment of fever, the primary symptom of simple malaria and other childhood illnesses, ${ }^{13,14}$ have established that acute febrile illness tends to be managed hierarchically, with initially convenience and cheaper options dominating before other alternatives are explored. Convulsions, which indicate severe malaria, tend to be perceived as a different disease with a separate etiology. ${ }^{15-18}$ With the malaria risk unevenly distributed across urban environments, ${ }^{19}$ interventions must be preceded by identification and prioritization of the most vulnerable, ie, children under 5 years. Despite the fact that access to quality health care is better on average in urban than in rural zones, formal public health facilities are often the last sources of treatment used along the pathway to care. ${ }^{19}$ In addition, in the urban areas, there is a lower predictive value of fevers $(20 \%-25 \%)$ compared with the rural zones, where fever is assumed to be malaria. ${ }^{19}$

In Cameroon, the prevalence of malaria is estimated at $8 \%,{ }^{20}$ but this may be an underestimation because the actual prevalence is not known. Malaria transmission in the country is all year round and the disease is a serious public health problem, accounting for $40 \%-45 \%$ of medical consultations, $57 \%$ of hospitalization days, and $40 \%$ of mortality among children under 5 years. ${ }^{21}$ In the country, more than $50 \%$ of fevers are treated at home. ${ }^{22}$ Studies by Nsagha et $\mathrm{a}^{23}$ have shown that whereas home management of malaria in Cameroon is very common, knowledge of the treatment dosage for malaria is poor. Einterz and Bates ${ }^{24}$ noted that $87 \%$ of patients and caretakers of children in Northern Cameroon have a poor ability to recognize fever. Knowing how to deploy ACT best at the community level as part of HMM is important. There is a need to test all children presenting with fever for malaria using a rapid diagnostic test before giving treatment, to avoid wastage of expensive ACT. High attrition rates for drug distributors have been recorded in some HMM strategies in Africa. ${ }^{25}$ There is a need to explore the possibility of introducing a nominal cost for ACT as an incentive to drug distributors. This study will help us to understand the community perception and response to childhood malaria episodes in an urban setting.

In response to the malaria burden, the Cameroonian Ministry of Public Health has developed a kit for HMM as a major component which is not yet fully operational, so a rapid diagnostic test is not used. To strengthen the rationale for use of antimalarials in the home, we explored the use of ACT for HMM in children under 5 years in an urban setting. This study was carried out to provide data on the feasibility of HMM in urban settings with respect to the baseline situational analysis of beliefs and practices in health-seeking behavior and drug use among community members, map sources for identification of the most suitable distribution channels for ACT, determine the acceptability of rapid diagnostic testing to confirm malaria in children under 5 years, and determine if a nominal cost for a rapid diagnostic test for malaria would be acceptable at the community level in the HMM strategy and an acceptable incentive for community drug distributors to perform well.

\section{Materials and methods Project area}

The study took place in the Bonassama health district in the city of Douala in the Littoral Province (now called Region) of Cameroon in 2006. The population of Douala is about 1.5 million, organized into six health districts. Douala is a flat, swampy area with a lot of stagnant water and garbage cans that act as breeding sites for mosquitoes. The housing conditions in the town are generally poor, with the well 
being the main source of water. The inhabitants of Douala come from most of the over 250 ethnic groups in Cameroon and also from other countries with different sociocultural backgrounds. Many of the inhabitants participate in artisan jobs, small trading, or hawking, or are unemployed, with few having salaried jobs. The area contains many small trading and artisan shops. The climate is made up of two distinct seasons, ie, a long rainy season from March to September and a short dry season from October to February. Temperatures can vary from $25^{\circ} \mathrm{C}$ in the rainy season to about $32^{\circ} \mathrm{C}$ in the dry season. Malaria is the main mosquito-borne disease in the locality and, as such, is a public health problem of primary importance. The six health districts of Douala include Bonassama, Deido, Nylon, Log Baba, Cité des Palmiers, and New Bell. The Bonassama health district is separated from the other five health districts by the River Wouri that empties into the Atlantic Ocean. This health district is a marshy, swampy, hot, humid region divided into 12 health areas. In order to carry out this research, the Bonassama health district was divided into two different areas based on the main road that passes through the health district. The coastal industrial area where the district hospital is located is the center, with the outskirts considered as the "periphery", and in between are the "intermediate/residential" areas. While this classification bears no relationship to the administrative zones, it was relevant for us in terms of conducting the qualitative survey effectively.

\section{Qualitative exploratory techniques}

This exploratory research combined a range of qualitative methods, whereby multiple techniques were used for data collection. The multiple techniques included a participatory approach and cross-cultural consultations with district medical officers, chiefs of health centers, health personnel, traditional rulers, and members of dialog structures. This strategy enabled the triangulation of data to capture the study variables. A range of variables were investigated, comprising beliefs and knowledge about malaria in the community, health-seeking behavior for malaria in children younger than 5 years, perception of rapid diagnostic testing and prepackaged ACT, preferred communication channels, role of the community in supporting HMM, and motivation of community drug distributors.

\section{Selection methods for focus group discussions and in-depth interviews}

Fifteen focus group discussions and 20 in-depth interviews (Table 1) were conducted using a guide to gather information on the major themes of the study. One hundred and eighteen people from different sociodemographic backgrounds participated in the focus group discussions and 20 in the in-depth interviews. Selection of the participants was based on occupation, role in home care for children under 5 years, location within the health area, age, gender, place of work, and type of health care provider. There were 68 women and 50 men. The participants in the focus group discussions were purposively chosen, in which minigroups of 4-8 and 9-12 people were drawn from the target population ${ }^{26-28}$ and discussed topics on HMM. The groupings were based on the age, gender, occupation, literacy, and social status of participants. Direct interviews were conducted in Pidgin English, English language, or French language and, in some cases, with the help of a trained interpreter. There was a moderator and note taker in all the focus group discussions. All the focus group discussions and in-depth interviews were recorded on audiocassette tapes. The purpose of taping the interviews was explained to the participants and their consent was obtained before this was done. The notes and replayed cassettes were transcribed after the interviews.

\section{Ethical clearance and administrative procedures}

Ethical clearance for this study was obtained from the National Ethics Committee of the Ministry of Public Health, Yaoundé, Cameroon, and the WHO Ethics Committee in Geneva. After a preliminary introduction of the study to administrative, traditional, and public health officials of Douala City to seek their support, the Bonassama health district was selected and the ethical clearance was presented to management. The purpose of the study and its advantages for children's health were explained, and questions raised by the staff were answered. Participants were asked to give their consent before the commencement of focus group discussions and in-depth interviews. Each participant was free to continue or abandon the process at his or her convenience. It was agreed that the identities of the participants would be concealed during the research process, analysis, and reporting.

\section{Sample size and selection}

The judgment sampling method was used in selecting the study participants. The participants were purposively selected to ensure that operationalization of the study variables was consistent for all participants. This is an appropriate sampling technique for the selection of a few cases for intensive studies in life history research. The sample size consisted of 
Table I Sample of the participants who took part in focus group discussions and in-depth interviews in the Bonassama health district

\begin{tabular}{|c|c|c|c|c|}
\hline \multirow[t]{2}{*}{ Data collection methods } & \multirow[t]{2}{*}{ Sources of data } & Area I & Area 2 & \multirow[t]{2}{*}{ Total } \\
\hline & & \multicolumn{2}{|c|}{ Number of FGD } & \\
\hline \multirow[t]{9}{*}{ FGD } & Mothers $<24$ years & I & I & 2 \\
\hline & Mothers $>24$ years & 1 & 1 & 2 \\
\hline & Old women & 1 & 1 & 2 \\
\hline & Men & 1 & I & 2 \\
\hline & Community health workers & I & I & 2 \\
\hline & Community drug distributors & I & 1 & 2 \\
\hline & Community guides & I & I & 2 \\
\hline & Technical advisers to community & I & & I \\
\hline & health workers (area I + area 2) & & & \\
\hline Total FGD & & $7+7+1$ & & 15 \\
\hline \multirow[t]{11}{*}{ IDI } & & Number & & \\
\hline & Caregivers & $\mathrm{I}$ & 1 & 2 \\
\hline & Opinion leaders & I & 1 & 2 \\
\hline & Pharmacists & I & 1 & 2 \\
\hline & Shopkeepers & 1 & 1 & 2 \\
\hline & Chemical sellers & 1 & 1 & 2 \\
\hline & Nongovernmental organizations & I & I & 2 \\
\hline & Private clinics/hospital operators & I & 1 & 2 \\
\hline & Community health workers & 1 & I & 2 \\
\hline & Health managers & 1 & 1 & 2 \\
\hline & Health care providers & 1 & 1 & 2 \\
\hline Total IDI & & 10 & 10 & 20 \\
\hline
\end{tabular}

Abbreviations: FGD, focus group discussion; IDI, in-depth interviews.

78 participants who took part in focus group discussions of 4-8 members and 60 participants of 9-12 members selected from a number of categories, including mothers younger than 24 years, mothers older than 24 years, old women, men, community health workers, community health workers, community guides, caregivers, opinion leaders, pharmacists, shopkeepers, chemical sellers, nongovernment organization leaders, private clinics/hospital operators, and health managers (Table 1). Twenty participants also took part in the in-depth interviews.

\section{Conducting focus group discussions and in-depth interviews}

We started by categorizing participants for focus group discussions/in-depth interviews into the groups cited earlier. Through the assistance of community guides (who were identified and selected by community health dialog structure members), we identified participants for focus group discussions and in-depth interviews. The addresses of participants and their telephone contact numbers were taken, and they were subsequently invited for focus group discussion at the Bonassama health district hospital. Key informants for indepth interviews were met at their residences.

During focus group discussions/in-depth interviews, there was a moderator, a note taker, and a person for tape recording the discussions. Participants for focus group discussions/ in-depth interviews were purposively selected to represent the two sections of the study area. At the end of each focus group discussion/in-depth interview, each cassette was labeled and stored in an envelope bearing the same label and the booklets of note takers to avoid confusion during translation.

\section{Typing and transcription of qualitative data}

After typing of the focus group discussions/in-depth interviews, they were given coded names, and each focus group discussion/in-depth interview was saved under a specific folder as a separate file. Taped interviews were handed over to secretaries who participated in the data collection process for transcription. Each transcribed focus group discussion/ in-depth interview bore the name labeled on the envelope and cassette. Transcription was done verbatim and Pidgin/ French interviews were translated into the English language. Typing of focus group discussions/in-depth interviews was done immediately after translation. The typing was carried out both by secretaries who participated in the transcription and other secretaries who were hired for the purpose.

\section{Development of code tree and analyses of qualitative data}

We created a code tree for the qualitative data analysis. This structure handled all the themes of the study. A branch 
of this figurative tree represented a major research theme. In some cases, a branch was divided into sub-branches or codes, corresponding to subthemes. In this case, each branch or subbranch handled a code. All qualitative data of the same theme were assembled under a code representing that theme.

\section{Coding qualitative data}

Sections of qualitative data were read and copied into the branches of the code tree that represented the themes. After all focus group discussions/in-depth interviews had been thoroughly treated following this procedure, each theme with its corresponding data were retrieved, read, and similar ideas were grouped separately. Common comments are presented in quotation marks in this paper.

\section{Results}

\section{Community perception of malaria}

Malaria in the Bonassama health district was perceived very differently by different categories of persons. Female caregivers, community guides, and nurses were of the opinion that malaria is a disease caused by mosquito bites. Female health workers perceived a child to have malaria when the body temperature was very high and the child developed fever. There were many signs as perceived by the local people. For example, the child becomes restless and the temperature keeps rising to $40^{\circ} \mathrm{C}$ and above. Some participants reported that when a child starts convulsing, they think of malaria. When convulsions start, malaria and witchcraft are taken to be synonymous, and they perceive the signs and symptoms of malaria to mean witchcraft. In this situation, they think that witches have attacked the child. Some also mistake malaria to mean infection of the spleen. The following comment was expressed by nine $(45 \%)$ of the in-depth interview participants.

"Fever is when temperature is very high. When you touch the child, you feel heat. The child may start to develop contractions, becomes restless and the eyes turn. When this happens, you know that it is malaria."

Most focus group discussion participants had incorrect views of malaria, as indicated in the following comment:

"When the child's body temperature is very high and he/she convulses, people know that this is malaria. It is also thought to be due to witchcraft. The mother would say that the child is a victim of witchcraft and has developed high body temperature or convulsion. To remedy this situation, the child is taken to the native doctor."

Female caregivers and community health workers mentioned common signs, like headache, joint pains, change of eye color, crying, and even convulsions. Mothers stated that fatigue, inactivity, inability to eat and drink, and shivering were signs of malaria. Men were also unanimous about paleness as a prominent sign of malaria. Older mothers insisted on cracked lips, running nose (catarrh), and red eyes as signs that the child has malaria. Community guides also mentioned all the other signs, and added swollen eyes and hallucination as indications of malaria in children. A summary of the findings on the perception of malaria by various categories of participants is shown in Table 2. Few differences were observed according to age group and gender.

\section{Actions taken at home by mothers/ caregivers of children with malaria}

Shopkeepers and younger and older mothers reported that mothers and caregivers first either wet the child with a towel or simply bath the child with cool water in an attempt to lower the temperature, followed by giving drugs such as paracetamol and quinine or nivaquine before thinking of the hospital. In the absence of drugs at home, some of them administer traditional concoctions, which they perceived to be useful and harmless, to calm the fever.

Table 2 Perception of malaria by various categories of participants who took part in focus group discussions and in-depth interviews

Perception of malaria

Disease caused by mosquito bites

High temperature and fever

Restlessness, eyes rolled, raised temperature

Convulsion

Witchcraft

Spleen infection

Headache, joint pains

Crying, inability to eat/drink, shivering, fatigue, inactivity

Paleness

Cracked lips, catarrh, red eyes

Swollen eyes, hallucination
Categories of participant who expressed such views

Female caregivers, community guides, nurses

Female health workers, female caregivers, mothers

Female care givers, mothers

Mothers, old women, female caregivers, community health workers

Mothers, old women, men

Mothers, female caregivers, old women, men

Female caregivers, community health workers

Mothers, female caregivers, community health workers

Men

Old mothers, female caregivers, community health workers Community guide 
"She is forced to wet a towel and put it on the child to lower the body temperature and avoid convulsion. When the body temperature rises to a certain level, the child convulses. After wetting with the towel, there are other means to keep temperature low. Suppositories are inserted into the anus. Amodiaquine syrup is also given since it is currently found in the market. When the situation does not improve, the child is taken to a health facility where examinations are conducted."

"Mothers generally wet the towel and put on babies. When there are no drugs at home, certain herbs are harvested and given to the child. The child is bathed with the herbs since these are not expensive. Some herbs are used to purge the child and malaria subsides later."

According to community drug distributors, alternative forms of malaria treatment consisted of rubbing the baby's body with castor oil (commonly known as "menyanga") before administering drugs after some hours of rubbing the child with a concoction of honey and menthol. These are strategies used to lower the child's body temperature.

"When my child has developed high body temperature,

I rub a bit of castor oil all over his heads, legs and feet. After

some hours, I give quinine to lower the temperature."

Contrary to what the other participants described as first-line home treatment, female health workers strongly disapproved of what mothers/caregivers do at home when children develop a high temperature. According to them, inappropriate treatment regimes are administered when children present signs and symptoms of malaria. Drugs like metronidazole, cotrimoxazole, and mebendazole were perceived to be effective malaria drugs by caregivers. Apart from the mere administration of inappropriate drugs, some mothers also proceed to purge children who present with signs and symptoms of malaria.

"You will be surprised to hear that a child who is having high temperature is being given flagyl or bactrim or efferalgan. For those who know, they can give efferalgan, but it is surprising that a child with high temperature, the mother is giving bactrim, or vermox to treat malaria. Since chloroquine is no more in the market, some of them buy it from hawkers."

Health managers, shopkeepers, and private clinic operators were of the opinion that whenever children have malaria, mothers and caregivers go straight to shops, markets, and private drug vendors for first-line drugs. Most of the time they use drugs which have been banned, like chloroquine. Some also use inappropriate drugs like cotrimoxazole. They only think of the hospital when the situation is almost out of hand, ie, when the child has already developed signs of severe malaria. They stated that what mothers and caregivers do at home for the treatment of malaria is inappropriate.

\begin{abstract}
"Their first action is to go to the road side drug hawkers where the quality of drugs is doubtful. This is because hawkers are found all over the quarter. Their action is to see whether high temperature can be lowered. This is the first action because she is the person who is most of the time at home. It is only when it is beyond their capacity that they go to the hospital when the child has developed signs of severe malaria."
\end{abstract}

\section{Difficulties faced by mothers in HMM for children}

Participants enumerated several difficulties faced by mothers treating children suffering from malaria. Drug sellers cited the frequent change of malaria drugs by the Ministry of Public Health, which creates confusion in the minds of caregivers. Other health care providers complained that mothers and caregivers do not know the dosages of some of the drugs administered to children, coupled with an inability to read the child's temperature. Mothers did not understand what malaria is because of ignorance. Some were ignorant to the point that they did not understand the dangers associated with the disease. Other major difficulties faced by mothers according to all the participants, and especially health care providers, were financial constraints and lack of appropriate drugs in the home. Some children developed severe malaria at home, not because their mothers or caregivers do not take them to hospital, but because they are unable to afford treatment. Poverty rendered some of them unable to afford 200 FCFA (about 2 USD) for treatment.

\begin{abstract}
"When children develop signs of malaria, the mother first wets a towel and wraps the child with in an attempt to lower the temperature. There is a need to have a thermometer at home. It is our wish that this should be available at home so that the management of simple malaria can be possible. Mothers should also keep some drugs at home, such as antipyretics. They should be trained to give these drugs."
\end{abstract}

\section{What mothers should do when children have a high temperature}

Drug sellers were of the opinion that mothers should protect their children by using mosquito nets. Female health care 
providers and private clinic operators insisted that mothers should do everything possible to start appropriate HMM before bringing babies to the nearest health facility, rather than taking inappropriate actions, such as putting the child's head into the toilet. Clinic operators and nurses indicated that mothers and caregivers should have thermometers at home, to take the baby's temperature and ascertain the severity of illness, and keep basic drugs such as paracetamol, amodiaquine syrup, or ACT at home in case the child develops a high temperature.

\section{Role played by fathers and male relatives when child has malaria}

The role of fathers and male relatives in this community was perceived by female caregivers to involve maintaining hygiene in the physical environment, draining away stagnant water, clearing dirt away from the residential area, and purchasing insecticide-treated nets for the family. All informants were unanimous about fathers and male relatives' responsibility for provision of financial assistance to the family when children suffer from malaria. They perceived fathers and male relatives as breadwinners for the family. They cited the absence of fathers and male relatives from home most of the time. Some female participants indicated that the provision of money is not as burdensome as taking care of a sick child at home and, worst of all, in hospital. However, the majority were of the opinion that financial provision is the most important aspect of the responsibilities of fathers and male relatives. Young female mothers were of the opinion that fathers and male relatives do not really care about the health of their children.

\footnotetext{
"It is true that the majority of young mothers have children whose fathers are very far away. When these children are sick, grandparents do not directly react. They tend to ask the whereabouts of their real fathers. Within this time lapse, young mothers go to roadside drug vendors. These drugs are popularly referred to as cassava powder."
}

Other female participants stated that fathers and male relatives do assist them with household chores like cooking, washing dishes, and taking care of children when they are sick. Some fathers and male relatives also accompany their children to health units and hospitals. Finally, fathers and male relatives play a supervisory role in confirming when they come back from work that the child's treatment was properly administered. Some fathers and male relatives examine children's treatment booklets or cards. They also advise mothers and caregivers to take children to health facilities when they are sick.

\section{Where mothers seek therapy for children with malaria}

There were many therapeutic options for HMM in our study area, including roadside drug vendors, drugs from drug stores (not operated by trained pharmacists), pharmacies, health centers, clinics, hospital-based treatment, and traditional or alternative treatment. Community drug vendors, community guides, and nurses stated that when children suffer from malaria, mothers come to them first and are offered all kinds of malaria drugs. It is only when the illness persists that children are taken to the nearest health facility. Health personnel and private clinic operators ventured some reasons why mothers prefer roadside drug vendors to health centers and hospitals.

\footnotetext{
"The roadside drug vendors do not charge consultation and laboratory fees; they do not demand a treatment card as a prerequisite for treatment."
}

When caregivers must seek hospital services, they often go to the CEBEC Protestant Hospital, which is located within the health district. This hospital is well attended because it provides drugs according to the severity of the disease and age group, and only gives the exact doses that are required to cure the disease. By so doing, mothers are faced with less financial expenditure. This is in contrast with government health facilities, where whole packets of drugs are prescribed even when only a few will be used.

"I have stayed in this quarter for long, when a child has fever, people rush to me. When I give treatment and the condition does not improve, I advise them to go to the protestant hospital where nurses handle malaria cases. Medical examinations are conducted and their drugs are relatively cheap. They also have very good pediatricians. They equally retail drugs. When you go there with 1000 francs, they will give you drugs worth 1000 FCFA. If you have 2000 FCFA, you will be given drugs worth this amount. Due to economic hardship, people prefer to go there for treatment."

Most of the health personnel were of the opinion that mothers take their babies to the nearest health centers or clinics because of lack of finance to cover the cost of transportation. They also prefer health centers because they receive the services of trained nurses. Shopkeepers and managers of health-related nongovernmental organizations were of the opinion that most mothers prefer private to public facilities. They are motivated by the presence of a relative or 
friend in the private health facility who would offer certain considerations regarding the means of payment and the possibility to receive treatment on credit and pay later on. However, some mothers and parents preferred the services of public hospitals because they have qualified personnel and a range of specialists. Health personnel, as well as older and younger mothers, mentioned that some mothers, before taking their children to a health facility, would first seek the services of soothsayers ("ngambe" men) and traditional healers. The reasoning behind this is they believe that there are some underlying causes of diseases that are not microbial. It is only after checking for an underlying or hidden cause of the illness and performing certain rituals that they go to the hospital for treatment.

"The majority of people prefer to go to roadside drug hawkers while some go to soothsayers. When children develop convulsion, they believe that they have extraordinary eyes. They will tell you that since your child is convulsing without high body temperature, you have to take him/her to the soothsayer. If not, witches will kill him/her. Most of them come back to the hospital when the cases are serious."

\section{Appropriate source of treatment sought by caregivers of children with malaria}

Opinions were divided regarding the most appropriate source of treatment for malaria in the Bonassama health district. The Bonassama District Hospital and the CEBEC Confessional Hospital were the most appropriate sources of treatment. Nurses, caregivers, health managers, and mothers were of the opinion that the Bonassama District Hospital is the most appropriate source of treatment for childhood malaria because of the presence of specialists, well trained nurses, very cheap drugs, and better laboratory facilities. Drug sellers, shopkeepers, and some mothers preferred the private and confessional hospitals for a range of reasons. The first reason was that the reception in this hospital is cordial. Secondly, they retail drugs, and parents only need to buy what is necessary for a specific bout of illness. Many poor parents are therefore attracted to this hospital. Thirdly, many people go to confessional hospitals for religious reasons.

\section{Perception of prepackaged ACT}

All participants were of the opinion that mothers appreciate prepackaged ACT for HMM because most are illiterate and usually find it difficult to manipulate drugs before administering them to their children. With prepackaged ACT, the doses are clear and easy to administer. Nothing is required except for education and awareness on the part of mothers regarding the importance of this new treatment strategy.

"Mothers will find this marvelous because they will master even the administration of the dosage. Even those who did not go to school will equally master it. The illustrations on the package will direct them. When the drugs are not prepackaged, they can easily misunderstand its usage."

Health managers and nurses were of the opinion that mothers would welcome the new approach because they do not always have access to drugs in the community. There is usually a barrier between the health system and the community. Bringing treatment into the home in the form of prepackaged drugs would solve most of the difficulties faced by mothers when their children suffer from malaria. Private clinic operators and shopkeepers also said that mothers would appreciate the strategy. Their worry was the drug formulation. Pre-packaged ACT is in tablet form for administration to children under 5 years of age. They wondered why the treatment was not in syrup form to facilitate administration. However, they concluded that mothers would grind the tablets before administering them to children.

"We are talking of prepackaged drugs for the treatment of children below 5 years. I would have preferred syrups. Maybe mothers can grind the tablets into powder before giving to the children."

Opinion leaders had a very favorable view of prepackaged ACT. If parents can have people around them who can come to their assistance with prepackaged drugs when children suffer from malaria, it is a laudable initiative. The only impediment, according to most of the participants, might be the price at which these prepackaged drugs are offered at the community level.

\section{Potential community distributors of ACT}

Community members were unanimous about the preferred distribution channels. They agreed that community health workers involved in routine vaccination campaigns should distribute the prepackaged drugs. They did not want nurses to be involved in the distribution because they felt that nurses have a tendency to sell drugs at their own prices. In communities where there are no community health workers, more need to be selected and trained. The main selection criterion should be their availability for work, because the drugs are supposed to be distributed throughout the day. Regarding the appropriate place in which to keep prepackaged ACT, 
some were of the opinion that it should be the quarter head's residence. Although local politics at the community level may often impact negatively on distribution, the quarter head's residence was still the preferred distribution venue and the preferred distributors were vaccinators who are well trained.

On the other hand, the majority of community members considered health centers or health posts to be the appropriate place for storage of drugs, the reason being that it would not be easy to access the quarter head's residence at any time of day. Secondly, health centers or health posts are found in all quarters and function all day round. Apart from this, small units could be created at the community level and managed by community health workers trained for this purpose. Thirdly, the quarter head's residence might not fulfill the requirements for storage of drugs. Trained community health workers who are vaccinators should be encouraged to go to health facilities and obtain the drugs for distribution.

\section{Willingness to pay for prepackaged ACT}

All participants were unanimous about the idea that mothers would pay for prepackaged drugs. What was needed was assurance that the medication is effective. If the medication is effective for malaria treatment, mothers will pay for it. Therefore, there is a need for effective communication within the community. Mothers could be educated and made aware of the importance of the drug. Health managers and nurses were of the opinion that price does not matter and that health has no price. According to them, mothers will pay even if the drug is expensive.

"People will be willing to comply under the difficult poverty conditions in Cameroon; but health has no price. If the ACT is effective like plasmotrim (12 tablets) which costs 3800 FCFA, people will pay to cure their children of malaria. Price cannot be a problem because, sometimes when we take children to the hospital, the child can receive 4 and 5 drips which are very expensive."

However, caregivers and mothers were of the opinion that price could be a major determinant of acceptability and adherence. If the drug is very expensive, it will kill any enthusiasm for the treatment. On the other hand, if it is cheap, most people will be willing to pay.

\section{Cost of ACT as perceived by community members}

Community members were of the opinion that the drugs should not be distributed free of charge but the amount should not be too high, taking into consideration the difficult economic situation in the country. When the price is too low, people might misjudge the value of the drug, and if it is too high, this might deter many people from using it. All participants agreed unanimously that there should be a price for rapid diagnostic testing and ACT. Several prices were given for the prepackaged drugs, including 100, 150, 200, 250, 300, 500, 600, 1000, and 1200 FCFA. Most community members were of the opinion that the price should not be more than 1200 FCFA, but the majority cited 500 FCFA for prepackaged drugs.

\section{Willingness of mothers to accept rapid diagnostic testing for their children}

All the participants stated that mothers would welcome the rapid diagnostic test. It was observed that, most often, it is mothers who request a blood test when they visit health facilities. The advantage of rapid diagnostic testing for mothers is that it saves time because results are immediately available. The strategy also saves money spent on transport to and from the laboratory. These advantages were particularly perceived by caregivers, all mothers, and drug sellers. Most mothers expressed a willingness to allow their children to be tested by finger-pricking. They cited many therapeutic practices for malaria within the community, which they perceived to be negative compared with ACT and the rapid diagnostic test. One of them reported burning the child's body or exposing the child to extreme heat in an attempt to cure malaria, which she mistakenly perceived to be failure of the spleen.

\footnotetext{
"We have to sensitize the people, when the people know that it is for their own good, they will do everything possible for their children to be tested and treated. It comes to mind that there is a very painful and primitive way of curing malaria or something they call 'spleen failure'. They burn the stomach of the child. You see that fire has been used on the child. If mothers can stand to see their child being burnt because they want them to be well, then what is the matter of just taking a pin, eh, prick the child's finger, get some blood, diagnose and treat the child. I think parents will accept that."
}

Opinion leaders and pharmacists were of the opinion that mothers would be in need of intensive education and sensitization on the importance of the procedure before they embrace it. Health care providers and community health workers insisted on involving community health dialog members in the sensitization of mothers and caregivers about the importance of the rapid diagnostic test. 


\section{Appropriate personnel to undertake rapid diagnostic testing}

There were divergent views on the right persons to carry out rapid diagnostic testing on children in the community. The choices were nurses, community health workers, and laboratory technicians. Community drug sellers, nurses, other health care providers, and younger and older mothers were of the opinion that the test should be conducted by nurses. However, they said that if it is going to be done in the community, the people responsible should have a certain level of education. The General Ordinary Level Certificate was the minimum level of education considered necessary for anybody conducting the test on children. Community guides and community health workers, young mothers, and some female health care providers were of the opinion that the test should be conducted by people involved in community health issues, such as vaccination. They argued that mothers and caregivers already have confidence in community health workers and community vaccinators, and that these people have good knowledge of how society functions.

"Vaccinators already know the importance of good health; they know the dose of drugs; they can teach their neighbors many things like going for the vaccination of their children. These vaccinators are community people because they collaborate well with everybody in the quarters. Since they are from my quarter, I cannot close my door to them when they are working or sensitizing the community."

The conclusion was that whoever is selected to conduct the rapid diagnostic test within the community should be given adequate education. They emphasized the issues at stake, such as human immunodeficiency virus/acquired immune deficiency syndrome, insisting that mishandling of blood under such circumstances would be catastrophic.

\section{Cost of rapid diagnostic testing}

None of our key informants were of the opinion that the test should be carried out free of charge. Participants suggested several prices, ranging from 100 to 2000 FCFA $(100,150$, 200, 250, 300, 500, 800, 1000, 1500, and 2000 FCFA). More than half of the informants cited 200 FCFA as the most appropriate price for the rapid diagnostic test. "There should not be a cost of prepackaged ACT separate from the cost of RDT." It would be reasonable to charge 500 FCFA for the cost of treatment, knowing that the cost of prepackaged drugs is 300 FCFA and the cost of the rapid diagnostic test is 200 FCFA.

\section{Obstacles likely to be encountered with HMM in children under 5 years}

Most health personnel, drug sellers, community guides, and men were of the opinion that there would be no difficulties in carrying out the rapid diagnostic test in children under 5 years. Just the simple fact that the results are given immediately renders the strategy plausible. They likened its rapidity to that of the pregnancy test. However, an obstacle could be the educational level and training of those who are to be involved in the execution of the test at the community level. If they are not well trained, they might misuse their tools, which would end up being discarded by the community. They should be trained, for example, on the importance of the use of one disposable needle per child.

\begin{abstract}
"The problems that we may face is when the RDT is conducted by someone who does not have the health knowledge; they could end up infecting the children. They might use one lancet on two or three children without sterilizing, or without discarding. If they don't have the basic knowledge on finger pricking technique, they might contaminate many children and the mothers might feel reluctant to bring their children for treatment."
\end{abstract}

Mothers and caregivers stated that because Douala is made up of people of diverse origins and backgrounds, the problem of tribalism is likely going to surface. In a Bamileke-dominated or Bassa-dominated quarter, people might not be ready to welcome a community health worker who comes from a different ethnic background and vice versa.

"Since I am not Bassa, working in a predominantly Bamileke quarter may cause problems of tribalism."

Mothers also cited religious beliefs as one of the obstacles which might affect HMM, especially concerning fingerpricking of babies. Many religious denominations do not allow children to be vaccinated or treated by manipulating blood, and believe that they can only be saved by God.

"I think there are some religions that don't want children to be vaccinated because they think that their religion would save them. Some religions would not allow any treatment. When one goes to them for any intervention, they would drive you away."

Opinion leaders and nongovernmental organization managers mentioned the logistics problems concerning the rapid diagnostic test, ie, it needs several associated materials, which might easily run out. Such materials 
include disposable lancets, cotton wool, alcohol, and plasters.

\section{Suggestions for improving HMM}

Community drug sellers and shopkeepers suggested the wearing of identification badges, bags, and caps with HMM messages to facilitate acceptability. People responsible for rapid diagnostic testing should be given gloves to protect themselves during finger-pricking. Drug sellers and clinic managers insisted that nothing is done for nothing nowadays, because volunteerism in the real sense does not exist, hence community drug distributors should be given some incentives. They raised the idea of combining the cost of ACT and rapid diagnostic testing. Given that they will not be distributed free of charge, a small percentage should be added for the distribution agents. If there are separate prices for prepackaged ACT and the rapid diagnostic test, confusion may arise and HMM could collapse.

\section{Preferred communication channels for social mobilization of HMM}

Participants cited several sources of information in the community, but thought there was some divergence of views, although some common ground was found. The sources where there were divergence of opinion concerned radio, television, and newspapers. The main sources of information on which nearly everybody agreed were community vaccinators, health dialog structure members, community chiefs, meeting houses ("njangis"), churches, and hospitals. Male and female community drug sellers, shopkeepers, young mothers, and pharmacy operators cited television and radio. They said that health radio and television spots are communicated most of the time in the French and English languages. Information through these sources could talk of the devastating effects of malaria on life and on the economy. According to them, this information comes most of the time from private rather than public media sources. Caregivers, health care providers, and opinion leaders cited community vaccinators, health dialog structure members, community chiefs, and churches as the main sources of information within the community. Information from the health district is sent to health centers via health dialog structure members who pass it down to the chiefs. The chiefs use the quarter heads who communicate directly with the rest of the population. In communities, vaccinators are used to going from door-to-door. Churches and meetings are also used as communication channels because there is always time reserved in meetings and churches for announcements. This is when health information is communicated to people who attend church services and meetings, who go home with the information, which is further circulated within the community.

\section{Preferred channel for communication of HMM strategy}

Many channels were discussed, but those who cited radio and television preferred private radio and television channels. They cited some local private media houses such as Radio Equinox, Sweet FM, and Canal 2. They were of the opinion that public media houses are more concerned with politics than with health. The church was identified as one of the more preferred communication channels. The argument was that because the majority of people go to worship houses, this will be the surest means, given that radios and televisions are not affordable to all, and many people might miss out on important information. Some were of the opinion that preachers should communicate health information in churches, because when information is communicated by pastors, people will take it seriously. Schools were also singled out as an important communication channel for passing on health information because children then pass on the information to their parents. Opinion leaders and nongovernmental organization managers preferred health information via flyers, posters, and banners. When flyers are distributed in meetings or churches, people take them back to their households. Because African households contain so many people, they could pass on the information to the rest of the community.

\section{Most effective communication channels for HMM social mobilization}

Although radio and television were cited among the most appropriate communication channels within the community, community health dialog structures emerged as an outstanding channel for communication. These are community health decision-makers and already live within the population. A community with an active community health dialog president has the chance to benefit in terms of communication. Alternative appropriate channels for communication within the community were churches and schools. Teachers and preachers are effective communicators in the community. Participants suggested that in addition to using community health dialog structures, these personnel should be approached for communication. Radio and television are good, but do not reach all the population strata. There are many houses without radios and television sets. Even when these are available, only a cross-section of the population watches and listens to them. Young people within the household might listen, but parents might not. 


\section{Additional information on improving HMM}

Participants were mostly concerned about the side effects of $\mathrm{ACT}$ and the price at which it was going to be offered at the community level. Mothers should be sensitized on possible side effects of ACT. Participants also sought clear information on the dosage so that mothers or caregivers could administer ACT safely and effectively. Community health care workers were eager to understand the signs and symptoms of malaria to differentiate the disease from other diseases in the community. There was still confusion between malaria and spleen enlargement. It would also be necessary to explain the philosophy behind the rapid diagnostic test to the population, and especially to mothers, telling them that it is necessary to conduct the test to diagnose malaria because there are several other diseases which might also lead to a high temperature, as well as telling them of the difficulties we might run into if $\mathrm{ACT}$ is given without the test and the problem of malaria drug resistance. Most mothers, both younger and older, were eager to understand the facts behind convulsions. This phenomenon is what frightens parents most. Often they perceived this to be attributable to witchcraft.

"If a drug is added to the treatment package to take care of convulsion, this will greatly help mothers; because very often we panic when a child convulses."

Understanding convulsions will help reduce tension in mothers. This will lead to rational decision-making about the treatment of malaria. Young mothers were eager to understand why the distribution of mosquito nets to pregnant mothers and households with children under 5 years is not effective. Many were also concerned about why all age groups were not offered the mosquito nets.

\section{Perceived role of participants in supporting HMM}

The participants perceived diverse roles which they could play in the provision of HMM at the community level. Community drug sellers stated that if they were given the opportunity to distribute prepackaged ACT, they would do everything possible to convince mothers and caregivers to give nothing but the drug. They were aware that most drugs they sell have been banned by the Ministry of Public Health. Female caregivers perceived their role in HMM to be limited to sensitization of mothers regarding taking children to the hospital and maintaining general hygiene and cleanliness. They could sensitize mothers to clear dirt from their environment and drain standing water to avoid breeding of mosquitoes.

Nurses and other health care providers thought that they would have a paramount role in educating and sensitizing the population, and especially mothers, on malaria and its devastating effects. They would ensure that mothers understand the risk of malaria infection and educate mothers and caregivers to understand what to do when children have malaria. They also thought that the prevention of malaria is more important than trying to cure it, hence the need to sensitize on the use of bed nets.

Health managers perceived their role as lying in the provision of HMM in the domains of community training, sensitization, and mobilization. Because health managers are the focal persons in the health district, they have the responsibility to train community members who are involved in health care delivery. Once community drug distributors are selected, they are the people to train them on effective communication techniques. They were also ready to train community drug distributors on monitoring and evaluation techniques. All mothers perceived their role to be limited in recognizing malaria at home and treating it following the new strategy. They knew that they were the first persons to deal with malaria at its onset. Meanwhile, pharmacists perceived their role as handling complicated cases of malaria.

\section{Main challenges of HMM at the urban community level}

The greatest challenge perceived by the participants was the efficacy of prepackaged ACT. Most participants stated that if ACT reduces fever among children within the first 3 days, many caregivers will adhere to it. Winning adherence in the community was one of the major challenges. Another challenge was overcoming reticence among religious groups, preaching by which sometimes prevents people from receiving effective treatment. Shopkeepers perceived reduction of drug cost as being problematic. They complained of the high cost of living and an increase in poverty. If it were possible for the treatment to be given at an affordable price, malaria among children would be effectively tackled.

\section{Solutions to challenges of urban $\mathrm{HMM}$ at the community level}

Community adherence should be won systematically as a gradual process because consent of the population is necessary. We have to enable them to understand from the outset that HMM is theirs, so that there will be no difficulties 
at the acquisition level. To overcome the problem of effective coverage in the community, many distributors have to be selected from all quarters so that people can have access to treatment at any time of the day and ensure that there are adequate stocks. We have to undertake effective education, sensitization, and mobilization of the community regarding the importance of HMM, and sensitize people to avoid an information void, which usually becomes filled by rumor. Training of those who are going to be directly involved in treatment is of the utmost importance, and includes training on how to handle the prepackaged drugs and on rapid diagnostic testing. Health managers also insisted on training community drug distributors about monitoring and evaluation of their own activities to avoid the errors that have arisen in other projects, like the distribution of insecticide-treated nets, which was welcomed by the community but was ultimately unsuccessful.

\section{Current motivational practices for community health workers}

Participants expressed diverse views about current practices for motivation of community health workers. Community drug sellers, shopkeepers, pharmacy operators, and mothers in all categories did not know about current practices of motivation for community health workers. All health personnel agreed that they used to give community vaccinators 1500 or 2000 FCFA per day for their involvement in the vaccination campaign. Those who were usually involved in sensitization were given 5000 FCFA a day for lunch, water, and taxi fares. This was not perceived as payment per se. Apart from the cash incentive, they were usually given a uniform (caps, apron, and badges) for identification purposes. This also helped to boost their standing in the community.

Health personnel felt that there were no problems with current motivational practices among community health workers. They estimated their work to be equal to the motivation given, because the work did not require a lot of talking. A simple whistle in the community during vaccination was more than enough signal for their work to start. Again, because vaccination is not an ongoing process, community health workers were not occupied all the time.

Community drug sellers and pharmacy operators were of the opinion that although they did not know what was being given to community drug distributors for their involvement in health programs in the community, they nevertheless knew that they were given something. "Nobody can work in Douala for a whole day for free," they said. They also expressed the view that for somebody to be happy, he or she should be paid a reasonable sum of money per day.

The district health manager was of the opinion that current motivational practices were enough to encourage those who take part in health activities in the community. Mothers thought that although they did not know what was being given to vaccinators, they believed motivating them was a good idea. They argued that these people need clothing, food, drinks, and other necessities of life. Therefore, they should be paid to compensate for their time and energy.

\section{Nature of preferred incentives for community drug distributors}

All participants agreed that incentives for community drug distributors should be monetary. They agreed that a cash payment was the best form of incentive. Two alternatives surfaced, ie, a daily incentive, which is a fixed sum of money paid to people who perform sporadic duties, and a percentage payment to those who perform ongoing duties. Community members who are co-opted to perform certain tasks for specific periods of time could be paid what was usually given to vaccinators, ie, 2000 FCFA per day. Those who were involved in ongoing activities, like the distribution of prepackaged drugs and rapid diagnostic testing, should be given a percentage of what they provide as the treatment package for malaria in the community. Drug sellers and shopkeepers recommended a purely market strategy for incentivizing community drug distributors. They stated that the project should add a tiny fraction to the cost price of the treatment of what they think could assist community drug distributors. At the end of each month, this fraction should then be calculated and given to each community drug distributor according to the quantity of ACT distributed.

"If the drug costs 300 FCFA, we can add 50 FCFA as gratification for the distributors; this puts ACT at 350 FCFA."

\section{Community contribution towards motivation of drug distributors}

Participants stated that community contribution could take several forms, moral, financial, and material. Mothers, shopkeepers, private clinic operators, and community drug sellers proposed that community members contributed directly to supporting HMM by buying the prepackaged drugs. If ACT is effective, many people will demand it, and those who are involved in its distribution will be paid by what the community offers as gratification for the purchase price of the drug. 
"If the ACTs are sold at a low price, and gratification is given to distributors, everybody will comply with the strategy. If the prepackaged drug costs 300 FCFA and the test costs 100 FCFA, we can add 50 FCFA as transport for the distributor and 50 FCFA as incentives. This puts the treatment package at 500 FCFA which according to me is not a problem for most families to afford".

Mothers also thought that community members could contribute by being friendly to those who distribute the drugs. According to them, once community drug distributors are supported morally, they will be very happy to execute their activities. Community members should not insult them. Nongovernmental organization managers thought that community contribution could take other forms, which are not easily perceived. Offering storage facilities and security for the rapid diagnostic test and prepackaged ACT and related materials was considered to be more than enough contribution. These are services which we should not expect the government to provide. Even the selection of community drug distributors is part of their contribution.

\section{Acceptable incentive for community drug distributors}

There was no consensus on an acceptable incentive for community drug distributors as per category of informants. Even within the same category, the suggested payments varied greatly. Those who understood the type of activities which community drug distributors were likely to perform proposed an additional 50 FCFA per dosage to the cost of treatment. Community drug sellers, shopkeepers, and nongovernmental organization managers proposed that an additional 50 FCFA should go to the community drug distributors for other community expenditures incurred in the provision of HMM. The incentive given to each community drug distributor should vary according to the quantity of ACT distributed.

\section{Potential challenges to motivation of drug distributors}

There were many challenges identified as facing the motivation of community drug distributors. One of these was how to make community drug distributors happy with what they receive as motivation. Another potential challenge was sensitization of the population. Once the population is effectively educated and sensitized about the importance of the new malaria treatment strategy, the project would move forward well. Initially there would not be any mass movement of the drug. Shopkeepers and drug sellers were of the opinion that a small proportion of the population has to start using the treatment and the rest will follow. The greatest challenge according to health managers was autofinancing of rapid diagnostic testing and ACT by the community. They were worried about community appropriation and sustainability. Apart from the motivation of community drug distributors, there was a need for the community to be able to replenish the rapid diagnostic test and prepackaged ACT in an ongoing way. How to revolve the autofinancing fund was a big challenge. Another potential problem was getting honest people at the community level to handle HMM, because the strategy entails handling money and materials.

"Those who were supposed to distribute ACT and rapid

diagnostic test will handle money from their sales."

Another potential challenge was overcoming religious obstacles. There are many religious groups, the ideologies and preaching of which do not allow children to be taken to hospitals or do not permit the manipulation of human blood, such as the Jehovah's Witnesses and Pentecostal churches. Participants emphasized the need to overcome these barriers in society, taking into consideration the fact that adherence is a major determinant of feasibility.

\section{Discussion}

This study was carried out to determine the community perception and treatment response to childhood malaria episodes in an urban setting prior to the implementation of the home management strategy. These findings are helping in the implementation of HMM of malaria in Cameroon. Importantly, our study has shed light on the feasibility of HMM in an urban setting. We identified and analyzed the following feasibility determinants of HMM in urban settings: beliefs and practices regarding health-seeking behavior and drug use in the community; the most suitable distribution channels for ACT; acceptability of rapid diagnostic testing to confirm malaria in children under 5 years before administering ACT; a nominal cost for a rapid diagnostic test; and an acceptable incentive for community drug distributors to perform their work well. These factors have been confirmed by other studies as being important in the implementation of $\mathrm{HMM}^{25}$

Convulsions, which are a prominent feature of severe malaria, were perceived as a separate disease associated with evil spirits and witchcraft, a perception noted in other parts of Africa. ${ }^{15-18,29-32}$ Traditional healing was customary, and 
the first option for management of convulsions, even if this was likely to be followed by a hospital consultation. Such a practice might cause delays to appropriate and effective treatment. The perception that an injection would be fatal for convulsing children has been reported earlier, ${ }^{29}$ and might reinforce the use of traditional remedies. ${ }^{18}$ In this study, vomiting and failure to eat, suck, and/or drink, which are symptoms of severe malaria, were identified as marking the development of malaria, which is in agreement with findings from a perception study in Tanzania. ${ }^{18}$

The diverse perception of malaria within a given health district indicates how difficult the disease is to manage in an urban setting. People from different cultural backgrounds variously perceived the disease to originate from drinking dirty water, contaminated food items, or "the evil eye". These perceptions further compound the efforts being made to fight against the disease. Information, education, and communication for positive behavior change may become a very challenging issue for HMM in urban settings. This is consistent with what was found in two Ghanaian cities where malaria in the urban areas displayed a complexity that differs in many respects from the rural environment. ${ }^{33}$ Others suggested that when children are not protected and eat dirty food and drink contaminated water, malaria is the outcome. ${ }^{18}$ The different ways in which community members perceive malaria primarily reflects their view of the world.

Mothers and caregivers recognized malaria as a high temperature, and the first action taken was application of a wet towel or any wet material in an attempt to lower the temperature. This is a positive action which should be encouraged in the HMM strategy. Correct recognition of malaria at the community level by mothers and caregivers has been reported by Dunyo et $\mathrm{al}^{34}$ and by the WHO. ${ }^{35}$ Operational guidelines for HMM in Cameroon by the Ministry of Public Health in $2004^{36}$ also acknowledged the fact that mothers diagnose malaria in their children and administer empirical treatment with drugs from diverse sources. Our findings reveal that some mothers first try drugs such as paracetamol, quinine, and nivaquine, although these have developed resistance, and others resort to alternative treatment regimes, such as enemas, inhalation from pit toilets, and administration of inappropriate drugs, such as metronidazole, cotrimoxazole, and mebendazole. The use of inappropriate antimalarial drugs and alternative treatments has been reported by the WHO. Many of the actions taken at home for the treatment of childhood malaria are inappropriate. This has been confirmed by other Cameroonian studies. ${ }^{37}$ However, it is certain that mothers and caregivers always do something at home when children develop signs and symptoms of malaria.

Signs and symptoms of severe malaria were perceived to be related to different diseases. ${ }^{15-18}$ Spleen problems, convulsions, and hallucinations (all symptoms of severe malaria) were perceived to be unrelated events, treatment for which could only be found outside the hospital milieu. This further indicates how narrowly malaria and its complications are perceived in this community. Therefore, one of the difficulties mothers and caregivers face in treating malaria among children in this urban milieu is ignorance. Other studies in Cameroon have confirmed this. ${ }^{37,38}$ Inadequate knowledge of malaria treatment guidelines and irrational use of antimalarials has been reported in Cameroon. ${ }^{39}$ Added to this, are the frequent changes in the drugs used to treat malaria by the Ministry of Public Health and financial problems.

Seeking of treatment for childhood malaria outside the home in this study area was influenced by the way the disease is perceived by mothers and caregivers and the community at large. ${ }^{23}$ Those who understand the signs and symptoms of both simple and severe malaria go first to health centers and hospitals when treatment at home fails. Those who perceive signs and symptoms of simple and severe malaria to be different diseases go to soothsayers, traditional health practitioners, and spiritual healers, and only turn to health centers and hospitals as a last resort when complications set in. ${ }^{37}$ Therefore, treatment of severe malaria in this health district does not often begin in health centers and hospitals.

Mothers perceived prepackaged ACT positively because they always provide treatment at home for their children. If treatment is effective and affordable, and if correct education and sensitization is carried out, full adherence would be assured. Their willingness to pay for prepackaged ACT was attenuated by the price offered and its effectiveness against malaria. However, the majority considered 500 FCFA to be the most affordable price for rapid diagnostic testing and prepackaged ACT.

Community health workers and community-based vaccinators were singled out as the potential distributors of ACT because they have been working in other health-related interventions, like administration of vitamin A, distribution of mectizan for onchocerciasis control, poliomyelitis vaccination, and sensitization on human immunodeficiency 
virus/acquired immunodeficiency syndrome. The community has already won their confidence.

Participants were equally unanimous that mothers would readily appreciate and accept the rapid diagnostic test for their children. The argument was that mothers most often accept very strange and difficult treatment regimes for complicated malaria, some of which consist of blood-letting and the burning of children's body parts with severe heat in an attempt to treat malaria, what they termed "spleen failure". Therefore, the rapid diagnostic test will be appreciated as a simple treatment procedure, given that the goal of HMM is to bring treatment closer to the home. However, religious beliefs constitute a major obstacle to the rapid diagnostic test, given that some groups, such as Jehovah's Witnesses, forbid the manipulation of human blood.

Although participants acknowledged the presence of other mass media communication channels within the community, such as radio and television, they singled out social mobilization channels, such as groups and associations ("njangis", churches, and schools). As for sensitization, they preferred the door-to-door method for interpersonal communication. Posters and flyers were also suggested. This communication strategy has also been confirmed by HMM studies in Nigeria. ${ }^{40}$

An incentive for community health workers to perform their duties effectively in the context of HMM was unanimously agreed upon by all participants as a determinant of control for this disease. This is important for the sustainability of HMM in both rural and urban settings. A high attrition rate among trained community drug distributors has been reported from a number of HMM studies in Africa. ${ }^{25}$

\section{Limitations}

The major limitation of this study was rallying participants in an urban setting for focus group discussions and in-depth interviews, because most inhabitants of the region work long hours to pay for house rents and meet bills. This required a lot of persuasion to obtain participants, with a concomitant increase in the cost of the study. Also, some participants did not understand English or French, but this problem was solved by using Pidgin English, which is understood by most people in Cameroon. As noted elsewhere, ${ }^{18}$ data collection relied heavily on informant reports of normative behavior in response to questions posed in a context far removed from the immediate stress and uncertainty of managing a child's actual illness, which could lead to overstating perceived norms, and underestimating or downplaying the extent to which people deviate from the norm. There is a likelihood that the researchers themselves were perceived as representing the health service and had vested interests in the Ministry of Public Health, which would tend to skew responses towards expression of greater acceptance of disease concepts and treatment practices. ${ }^{18}$

\section{Conclusion}

Mothers in this study perceived malaria as an outcome of events other than mosquito bites. Home treatment of malaria is very common in the urban setting, and is guided by the way mothers perceive the signs and symptoms of the disease. The frequent changing of approved malaria drugs by the national health policy and financial difficulties were the main problems mothers faced in treating febrile children at home. Prepackaged ACT for simple malaria in children under 5 years of age and rapid diagnostic testing would be accepted if offered at an affordable price. Tribalism and religious beliefs might hinder the delivery of HMM. The availability of rapid diagnostic testing all year round is one of the challenges of HMM. Although radio and television figured among the current sources of information within the community, meetings, churches, schools and other public gatherings were considered to be the best venues for social mobilization, while community health workers and community leaders were considered to be the best sensitization agents for positive behavior change. Incentives for community drug distributors should be monetary, and could be deducted from the combined price of ACT and rapid diagnostic testing. For successful implementation of HMM, there should be proper education and social mobilization of the population. There should also be continuous monitoring and evaluation of community activities to ensure that there is ongoing availability of ACT and rapid diagnostic test stock within the framework of the intervention. More research is needed on HMM at the community level to improve identification, treatment, and referral of children with severe malaria, indicated by convulsions and inactivity, in order to improve child survival.

\section{Acknowledgments}

We are grateful to the Provincial Delegate of Public Health in Littoral Province, Dr Sone and the District Medical Officer of the Bonassama Health District, Dr Simon Mbunya and his staff for their collaboration, and the local population involved in the data collection. We thank Mr James Achanyi Fontem of Cameroon Link for mobilizing the local population. Mr Nguedjio Christophe was excellent in his translation and 
typing of the results. We are grateful to the Ministry of Public Health of Cameroon, all nongovernmental organizations, and field assistants working in Bonassama who collaborated in the data collection. This work received financial support from the United Nations Children's Fund/United Nations Development Programme/World Bank/WHO Special Programme for Research and Training in Tropical Diseases, Geneva, Switzerland.

\section{Disclosure}

The authors report no conflicts of interest in this work.

\section{References}

1. Orton LC, Barnish G. Unit dose packaged drugs for treating malaria [review]. Cochrane Database Syst Rev. 2005;2:CD004614.

2. Espina-Bertoso S. Malaria for the anaesthetist. Anaesthesia. Available from: http://update.anaesthesiologists.org/wp-content/uploads/2011/03/ Malaria-for-the-anaesthestist.pdf. Accessed August 15, 2011.

3. Bhattacharyu $\mathrm{S}$. The deadly rise of urban malaria. [webpage on the Internet]. London: Reed Business Information Ltd; Nov 30, 2004. Available from: http://www.newscientist.com/article/dn6740-the-deadly-rise-ofurban-malaria.html. Accessed Nov 2, 2011.

4. Brieger WR, Sesay HR, Adesina H, et al. Urban malaria treatment behaviour in the context of low levels of malaria transmission in Lagos, Nigeria. Afr J Med Med Sci. 2001;30 Suppl:7-15.

5. Nimpaye H, et al. Urban malaria in Yaounde (Cameroon) in 2000. Entomological studies in the "Dakar" Central quarter. OCEA Bulletin. 2000. French.

6. Brieger WR, Salako L, Umeh R, Agomo P, Afolabi B, Adeneye A. Promoting pre-packaged drugs for prompt and appropriate treatment of febrile illnesses in rural Nigerian communities. Int Quart Com Health Edu. 2002;21(1):19-40.

7. Okonkwo PO, Akpala CO, Okafor HU, Mbah AU, Nwaiweu O. Compliance with correct doses of chloroquine in uncomplicated malaria correlates with improvement in the condition of rural Nigerian children. Trans R Soc Trop Med Hyg. 2001;95(3):320-324.

8. Hamel MJ, Odhacha A, Roberts JM, Deming MS. Malaria control in Bungoma District, Kenya: a survey of home treatment of children with fever, bednet use and attendance at antenatal clinics. Bull World Health Organ. 2001;79(11):1014-1023.

9. Marsh VM, Muteni WM, Muturi J, et al. Changing home treatment of childhood fevers by training shopkeepers in rural Kenya. Trop Med Int Health. 1999;4(5):383-389.

10. Sirima SB, Konate A, Tiono AB, Convelbo N, Cousens S, Pagnoni F. Early treatment of childhood fevers with pre-packaged anti-malarial drugs in the home reduces severe malaria morbidity in Burkina Faso. Trop Med Int Health. 2003;8(2):133-139.

11. Pagnoni F, Convelbo N, Tiendrebeogo J, Consens S, Esposito F. A community-based programme to provide prompt and adequate treatment of presumptive malaria in children. Trans R Soc Trop Med Hyg. 1997;91(5):512-517

12. WHO. Scaling up home-based management of malaria: from research to implementation. WHO. 2004:1-94.

13. McCombie SC. Treatment seeking for malaria: a review of recent research. Soc Sci Med. 1996;43(6):933-945.

14. McCombie SC. Self-treatment for malaria: the evidence and methodological issues. Health Policy Plan. 2002;17(4):333-344.

15. Winch PJ, Makemba AM, Kamazima SR, et al. Local terminology for febrile illnesses in Bagamoyo District, Tanzania and its impact on the design of a community-based malaria control programme. Soc Sci Med. 1995;42(7):1057-1067.
16. Ahorlu CK, Dunyo SK, Afari EA, Koram KA, Nkrumah FK. Malariarelated beliefs and behaviour in southern Ghana. implication for treatment, prevention and control. Trop Med Int Health. 1997;2(5):488-499.

17. de Savigny D, Mayombana C, Mwageni E, et al. Care-seeking patterns for fatal malaria in Tanzania. Malar J. 2004;3:27.

18. Warsame M, Kimbute O, Machinda Z, et al. Recognition, perceptions and treatment practices for severe malaria in rural Tanzania: implications for accessing rectal artesunate as a pre-referral. PLoS One. 2007; 2(1):e149.

19. Donnelly MJ, McCall PJ, Lengeler C, et al. Malaria and urbanization in Sub-Saharan Africa. Malar J. 2005;4(1):12.

20. Soula G, Ndounga M, Foumane V, et al. Evaluation of the resistance of Plasmodium falciparium to chloroquine in Cameroon and alternative therapies. Bulletin of OCEA. 2000;33:13-22. French.

21. Ministry of Public Health Cameroon. National strategic plan to fight against malaria. 1-171. French.

22. Djoufack J. Study on malaria morbidity in Emombo quarters, Yaounde. Medical Thesis. Faculty of Medicine and Biomedical Sciences. University of Yaounde I, Cameroo. 1996. French.

23. Nsagha DS, Njunda AL, Kamga HL, et al. Knowledge and practices relating to malaria in a semi-urban area of Cameroon: choices and sources of antimalarials, self-treatment and resistance. Pan Afr Med J. 2011;9(8):1-20.

24. Einterz EM, Bates ME. Fever in Africa: do patients know when they are hot? Lancet. 1997;350(9080):781.

25. Ajayi IO, Browne EN, Garshong B, et al. Feasibility and acceptability of artemisinin-based combination therapy for the home management of malaria in four African sites. Malar J. 2008;7:6.

26. Fern EJ. The use of focus groups for idea generation: the effects of group size, acquintanceship and moderator on response quantity and quality. J Market Res. 1982;19:1-13.

27. Krueger RA. Focus groups: a practical guide for applied research. London, UK: Sage; 1988:1-11.

28. Khan ME, Anker M, Patel BC, Berge S, Sadhwani H, Kohle R. The use of focus groups in social and behavioural research: some methodological issues. World Health Stat Q. 1991;44(3):145-149.

29. Comoro C, Nsimba SE, Warsame M, Tomson G. Local understandings, perceptions and practices of mothers and health care providers on childhood malaria in a Tanzania district - implications for malaria control. Acta Trop. 2003;87(3):305-313.

30. Kengeya-Kayondo JF, Seely JA, Kajura-Bajenja E, et al. Recognition, treatment seeking behaviour and perception of cause of malaria among rural women in Uganda. Acta Trop. 1994;58(3-4):267-273.

31. Mwenesi HA, Harphan T, Marsh K, Snow RW. Perceptions of symptoms of severe childhood malaria among Mujikenda and Luo residents of coastal Kenya. J Biosoc Sci. 1995;27(2):235-244.

32. Aikins MK, Pickering H, Alonso PL, et al. A malaria control trial using insecticide-treated bed nets and targeted chemoprophylaxis in a rural area of The Gambia, west Africa. 4. Perceptions of the causes of malaria and its treatment and prevention in the study area. Trans $R$ Soc Trop Med Hyg. 1993;87 Suppl 2:25-30.

33. Klinkenberg E, McCall PJ, Wilson MD, et al. Urban malaria and anaemia in children: a cross-sectional survey in two cities of Ghana. Trop Med Int Health. 2006;11(5):578-588.

34. Dunyo SK, Afari EA, Koram KA, Ahorlu CK, Abubakar I, Nkrumah FK. Health Centre versus home diagnosis of malaria in Southern Ghana: implications for home-based care policy. Trans R Soc Trop Med Hyg. 2000;94(3):285-288.

35. World Health Organization. TDR Progress 1999-2000: Fifteenth progress report. Geneva: World Health Organization; 2001.

36. Ministry of Public Health. Operational Guidelines for Home Management of malaria in Cameroon. National Malaria Control Programme. June, 2004.

37. Nsagha DS, Njunda AL, Kamga HL, et al. Knowledge and practices relating to malaria in Ndu community of Cameroon: signs and symptoms, causes and prevention. J Public Health Epid. 2011;3(6):294-300. 
38. Lantum DN. The malaria problem in Cameroon in 1969. A demographic perspective. West Afr Med J Niger Pract. 1971;20(4):285-292.

39. Sayang C, Gausseres M, Vernazza-Licht N, Malvy D, Bley D, Millet P. Treatment of malaria from monotherapy to artemisinin-based combination therapy by health professionals in rural health facilities in southern Cameroon. Malar J. 2009;8:174.
40. Ajayi IO, Falade CO, Olley BO, et al. A qualitative study of the feasibility and community perception on the effectiveness of artemetherlumefantrine use in the context of home management of malaria in south-west Nigeria. BMC Health Serv Res. 2008;8:119.

\section{Publish your work in this journal}

Drug, Healthcare and Patient Safety is an international, peer-reviewed open-access journal exploring patient safety issues in the healthcare continuum from diagnostic and screening interventions through to treatment, drug therapy and surgery. The journal is characterized by the rapid reporting of reviews, original research, clinical, epidemiological and post-marketing surveillance studies, risk management, health literacy and educational programs across all areas of healthcare delivery. The manuscript management system is completely online and includes a very quick and fair peer-review system. Visit http://www.dovepress.com/ testimonials.php to read real quotes from published authors.

Submit your manuscript here: http://www.dovepress.com/drug-healthcare-and-patient-safety-journal 